\title{
Insecticidal Action of Glycerol Monolaurate against the Lesser Mealworm (Alphitobius diaperinus) and its Ecotoxicological Effect on Enchytraeus crypticus
}

\author{
Thainã Tomasi ${ }^{1}$, Talyta Zortéa ${ }^{1,4}$, Tamires Rodrigues dos Reis', \\ Leonardo Quintana Soares Lopes ${ }^{2}$, Matheus Dallamea Baldissera ${ }^{3}$, Roberto Christ Vianna Santos ${ }^{3}$, \\ Dilmar Baretta ${ }^{1,4}$, Lenita Moura Stefani ${ }^{1{ }^{14}}$ \& Aleksandro Schafer da Silva ${ }^{1,4}$
}

\begin{abstract}
Background: Alphitobius diaperinus, known as the lesser mealworm, is recognized as a problem for the poultry production sector. Several chemical methods have been employed in an attempt to control it, without successful results. Thus, alternative methods should be considered as an interesting approach to control this type of infestation. A recent study showed that glycerol monolaurate (GML) possesses insecticidal effect against bees. Therefore, the aim of this study was to evaluate, for the first time, the effect of GLM against the larval and adult forms of the lesser mealworm in vitro, and to verify whether GLM treated poultry litter used as soil fertilizer exerts any negative effect on its fauna.

Materials, Methods \& Results: In vitro tests were performed using three concentrations of GLM: 0.2, 0.4 and $1 \mathrm{mg} \mathrm{mL}^{-1}$, and the number of dead larvae and adults of A. diaperinus was counted on days 0,2,5 and 8 post-treatment. Poultry litter was pulverized with $1 \mathrm{mg} \mathrm{mL}^{-1}$ of GML, maintained under controlled conditions for 20 days and revolved every two days. Two ecotoxicological tests were performed using Enchytraeus crypticus. In the first test, GML was applied directly into the soil at doses of $0.5,1$ and $2 \mathrm{mg} \mathrm{kg}^{-1}$ of soil, while the second test used poultry litter as soil fertilizer at concentrations of 0,2, 4 and 8 tons per hectare. Insecticidal action of GML against larvae and adults of A. diaperinus where only the 1 $\mathrm{mg} \mathrm{mL} \mathrm{m}^{-1}$ concentration showed positive effect. GML caused $100 \%$ mortality of larvae two days after the beginning of treatment. Similarly, GML showed high efficacy to control adult forms of A. diaperinus, causing 83 and $90 \%$ of mortality on days 5 and 8 post-treatment, respectively. No difference was observed while applying GML directly at doses of $0.5,1$ and $2 \mathrm{mg} \mathrm{kg}^{-1}$ in the TAS when compared to the control group, similarly to what was observed using poultry litter containing $1 \mathrm{mg} / \mathrm{m}^{2}$ of GML at concentrations of $0,2,4$ and 8 tons per hectare compared to the control group.

Discussion: GML treatment exerted larvicidal and insecticidal action in vitro against $A$. diaperinus, similarly to what was observed by researchers against bees, where this product was able to eliminate $55 \%$ of the bees after $120 \mathrm{~h}$ of treatment. GML insecticidal mechanism of action is poorly investigated and remains unknown. However, there are evidences regarding its antimicrobial property using Staphylococcus aureus, Streptococcus spp., Enterococcus faecalis, as well as its capacity to inhibit some virulence factors linked to antimicrobial resistance. Some tests have been performed in order to reduce the use of chemical products, as Melaleuca alternifolia (tea tree oil), Ocotea odorifera (popularly known as sassafras) and Eucalyptus viminalis (popularly known as eucalypt) essential oils exerts insecticidal action against the larvae and adults of mealworms. The main chemical used to control A. diaperinus is cypermethrin, a chemical product that can damage the soil fauna due to its intensive utilization. The use of GML did not cause negative effects in the soil fauna, in disagreement other study with GML at concentrations of 50 and $100 \mu \mathrm{gL}^{-1}$ and found negative effects on the soil fauna using adults and juvenile forms of springtails (Folsomia candida) as biomarkers, showing a LD50 of $41 \mu \mathrm{g} \mathrm{mL}{ }^{-1}$. Based on these evidences, we can suggest that the toxicity of GML to soil fauna is related to the biomarker used to determine the toxicity. Therefore, it is possible to conclude that GML possesses insecticidal action without toxic effects for the soil fauna, demonstrating potential as an alternative method to control the lesser mealworm.
\end{abstract}

Keywords: mealworm, glycerol monolaurate, control, ecotoxicological test. 


\section{INTRODUCTION}

The control of mealworm (Alphitobius diaperinus) is recognized as one of the most important challenge for the development of the poultry business. The lesser mealworm is commonly found in poultry houses, mainly in humid environments [17] and rarely the lesser mealworm parasitizes the birds [8]. The most important problem regarding these insects is linked to their consumption by the birds, which could lead to lower feed intake. Moreover, the mealworm can be responsible for the dissemination of diseases causing severe economic impairment for the poultry industry $[4,11]$.

Several methods are used to control mealworms, being the use of chemical insecticides based on pyrethroids or organophosphates the main method employed. However, these drugs have limited efficiency and present a risk for meat contamination $[9,18]$. Study revealed that cypermethrin used in the control of mealworm exerts negative effects on the survival and reproduction of springtails [18]. Thus, is important the search of new methods to control the mealworm [2]. The use glycerol monolaurate (GML) in order to control mealworms it's a hypothesis, since this product showed insecticidal effect against bees [10]. The GML is a natural compound found in milk, coconut and palm oils, and other oils derived from lauric acid $[9,10]$. This product acts as a preservative inhibiting the proliferation of pathogens and avoiding food contamination $[1,13]$. The aim of this study was to evaluate GML insecticidal effect against larval and adult forms of the lesser mealworm, as well as to verify its residual effect on soil fauna fertilized by GML treated poultry litter.

\section{MATERIALS AND METHODS}

In order to obtain the expected results, this study was conducted in two tests (experiment I and II) using GML1.

\section{Experiment I}

Mealworms were collected from infested poultry houses in the west of Santa Catarina state (Southern Brazil), and kept in laboratory under controlled temperature (between $25-28^{\circ} \mathrm{C}$ ), and humidity (70\%). These insects were allocated into plastic cages containing moistened cotton and were fed with commercial broiler chicken feed.
For in vitro tests, mealworms (10 larvae (L8 stage) and 10 adults) were allocated separately into Petri dishes coated with filter paper in order to improve the distribution of the GML treatment. Based on a pilot study using $1 \mathrm{mg} / \mathrm{mL}$ of GML, three different concentrations were tested: $0.2,0.4$ and $1 \mathrm{mg} \mathrm{mL}^{-1}$. Distilled water was used as the diluted. A control group without GML was used to validate the tests. A volume of $300 \mu \mathrm{L}$ of each treatment was added into the Petri dishes containing the insects, that were maintained in an incubator $\left(27 \pm 1^{\circ} \mathrm{C} ; 70 \% \pm 10\right.$ relative humidity $)$. The number of dead insects (larvae and adults) were counted on days 1, 2, 5 and 8 post-treatment. The in vitro results showed normal distribution after the normality test. Thus, analyses of variance (ANOVA) followed by the Tukey post hoc test were used to evaluate the differences between groups considering $P<0.05$.

\section{Experiment II}

Before the beginning of the ecotoxicological tests, one sample of poultry litter was collected from a farm that did not use chemical products to control insects. This litter was used to rise a new flock of broiler chickens, and composed of wood shavings, feces, feathers and food scraps. In the laboratory, the litter was separated into two plastic cages $(40 \times 30 \times 15 \mathrm{~cm})$ allocated in a controlled environment $\left(25^{\circ} \mathrm{C}\right)$. One cage was pulverized with $50 \mathrm{~mL} \mathrm{GML}$ at dose of $1 \mathrm{mg} \mathrm{mL}^{-1}$, while 50 $\mathrm{mL}$ of distilled water was pulverized in the other cage (the control group). These cages were maintained under controlled conditions during 20 days, being revolved at two days interval. The humidity was also checked and maintained at 25-30\%, as observed in nature.

This study was conducted using the Tropical Artificial Soil (TAS) method proposed by Garcia [3], that is based in a soil adaptation. The $\mathrm{pH}$ of TAS was corrected to $6.0 \pm 0.5$ through the addition of $\mathrm{CaCO}_{3}$, and the water content was initially adjusted to $65 \%$ of maximum water holding capacity, as recommended by the ISO 11267 [7]. Earthworms (E. crypticus) obtained from laboratory cultures using the TAS method according to the ISO 11267 [7] were used as biomarkers of contamination. Weekly, E. crypticus was fed with an autoclaved diet containing fine ground oats and distilled water. The tests were performed using only adults (with clitellum) maintained in an acclimated room at $20 \pm 2^{\circ} \mathrm{C}$ and photoperiod of 12:12 h (light/dark).

The survival and reproduction assays were divided into two steps: a direct application of GML at doses 
of $0,0.5,1$ and $2 \mathrm{mg} \mathrm{kg}^{-1}$ of soil, and the use of pulverized poultry litter at $1 \mathrm{mg}$ per $\mathrm{m}^{2}$ (poultry litter $+\mathrm{GML}=\mathrm{PL}$ + GML), and other part that did not receive GML (the positive control, PL only). The assays using the poultry litter simulating the doses of organic fertilizer were applied in crescent doses $(0,2,4$ and 8 tons per hectare of poultry litter) and maintained in the laboratory for 8 days.

Regarding survival and reproduction tests using E. crypticus, we used methodologies standardized by ISO 16387 [6]. Each experimental unit received $30 \mathrm{~g}$ of soil (TAS) e the established doses of GML in poultry litter, as well as the control group. Later, 10 adults (with clitellum) E. crypticus were added. The organisms were fed in the beginning of the test and on day 14 , and received water weekly. On day 28 th, the number of juvenile and adult E. crypticus were evaluated after fixation with ethylic alcohol, colored with rose Bengal stain (1\% in ethanol) and wet sieving $(1 \mathrm{~mm})$.

The difference between doses and control were evaluated using a one-way analysis of variance followed by Dunnet post hoc test using the Statistica 7.0 software.
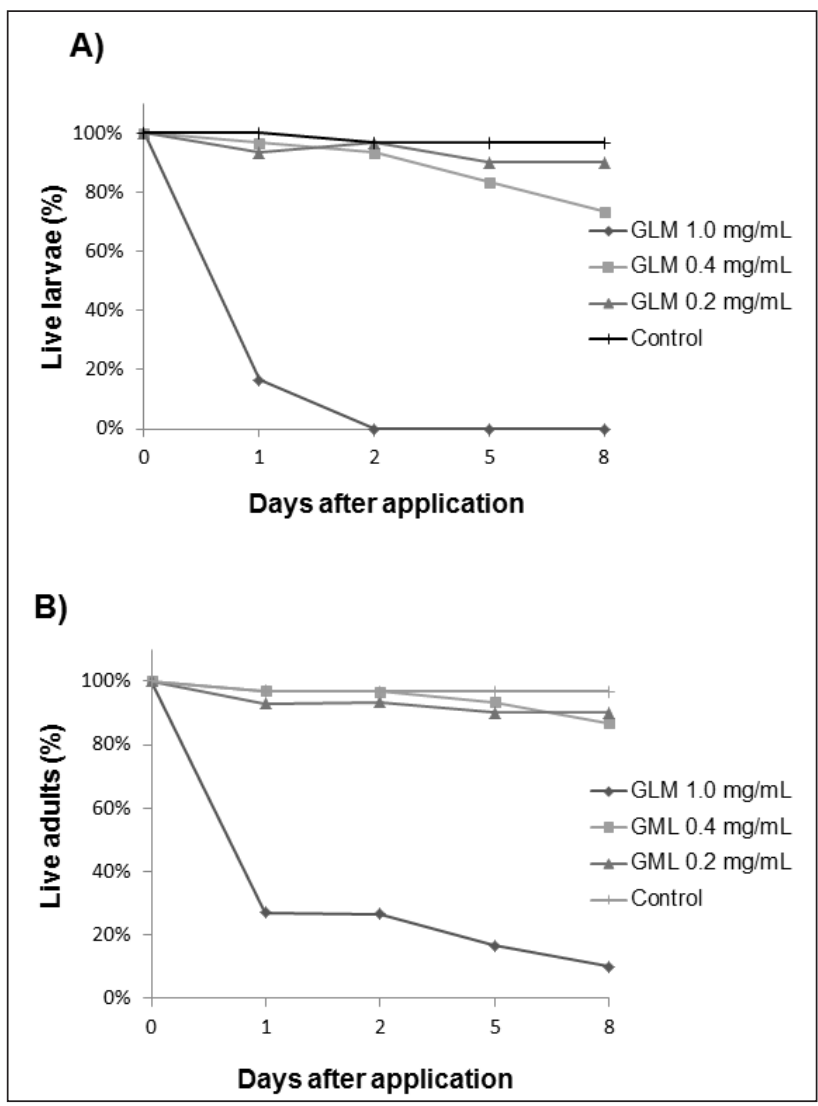

Figure 1. Percentage of live larvae (A) and live adults (B) of Alphitobius diaperinus after glycerol monolaurate (GML) application at concentrations of $0.2,0.4$ and $1 \mathrm{mg} / \mathrm{mL}$ using water as control.

\section{RESULTS}

\section{Experiment I}

Figure 1 (A, B) shows the insecticidal action of GML against larvae and adults of Alphitobius diaperinus where only the $1 \mathrm{mg} / \mathrm{mL}$ concentration showed positive effect $(P<0.05)$. GML caused $100 \%$ mortality of larvae two days after the beginning of treatment (Figure 1A). Similarly, GML showed high efficacy to control adult forms of $A$. diaperinus, causing 83 and $90 \%$ of mortality on days 5 and 8 post-treatment, respectively (Figure 1B).

\section{Experiment II}

No difference was observed while applying GML directly at doses of $0.5,1$ and $2 \mathrm{mg} \mathrm{kg}^{-1}$ in the TAS when compared to the control group (Figure $2 \mathrm{~A}$, B), similarly to what was observed using poultry litter containing $1 \mathrm{mg}$ per $\mathrm{m}^{2}$ of GML at concentrations of 0, 2, 4 and 8 tons per hectare compared to the control group (Figure $3 \mathrm{~A}, \mathrm{~B}$ ).

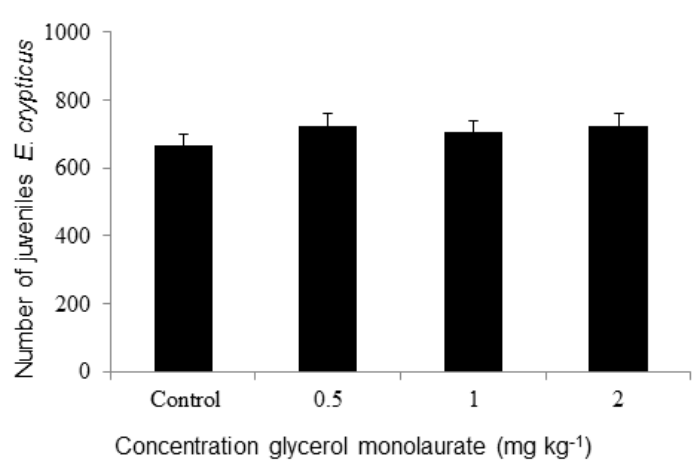

B)

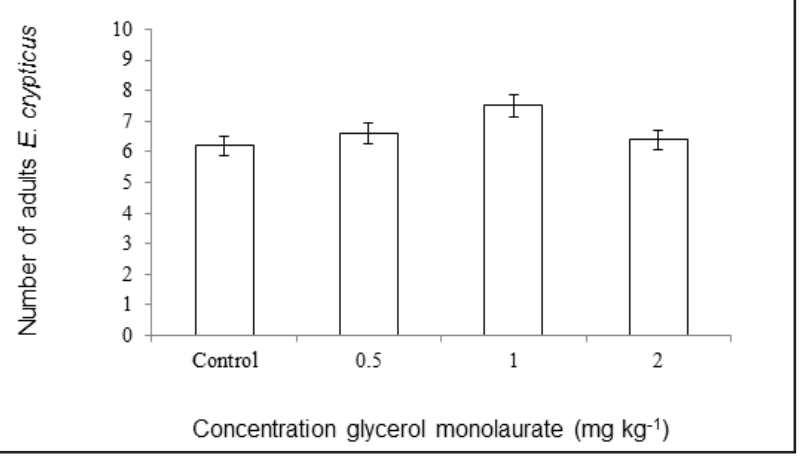

Figure 2. Reproduction (A) and survival (B) tests using Enchytraeus crypticus exposed to different concentration of glycerol monolaurate (GML) using the tropical artificial soil (TAS). The treatments were considered similar by Dunnet post hoc test $(P>0.05)$. 


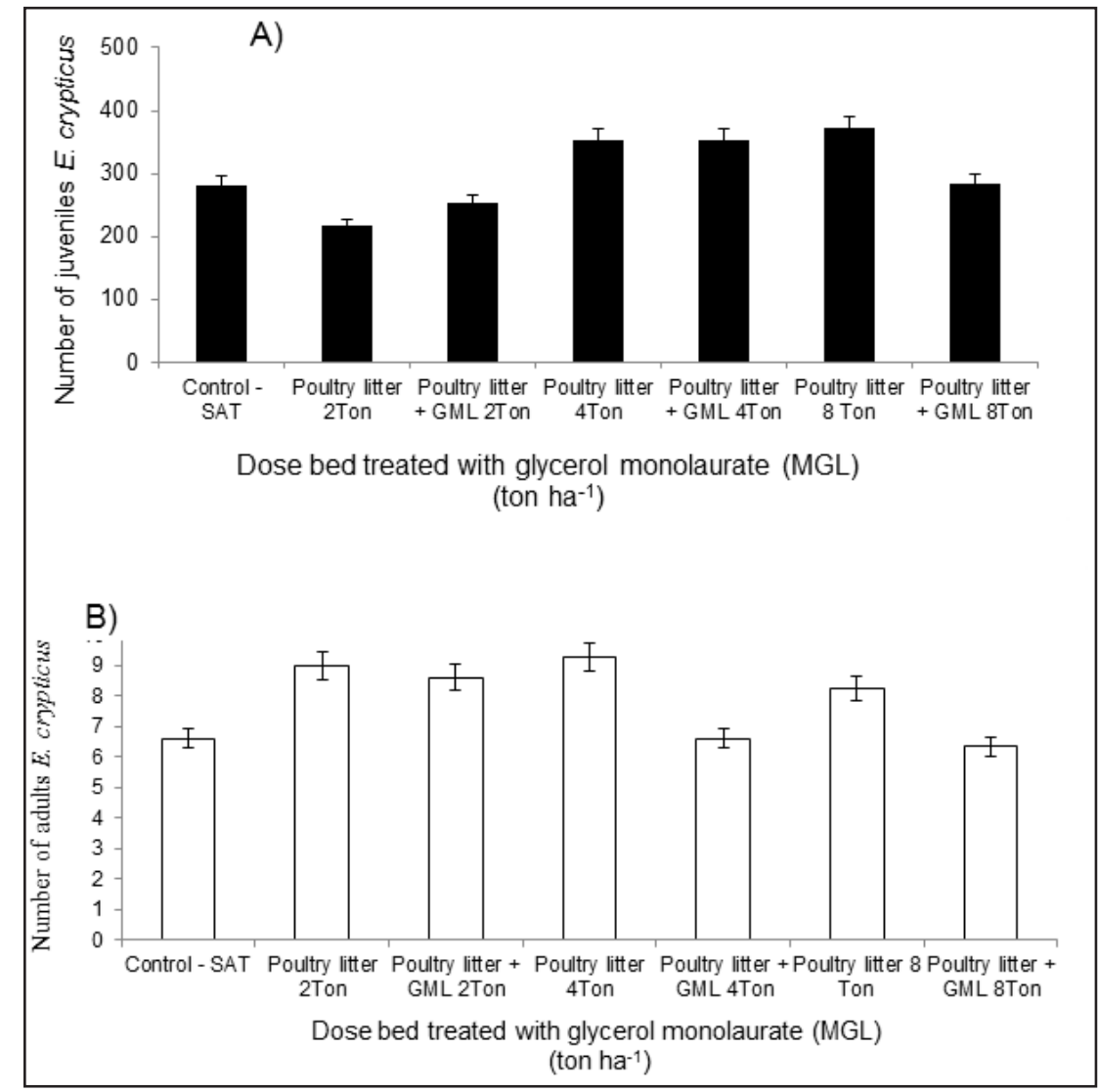

Figure 3. Reproduction (A) and survival (B) tests using Enchytraeus crypticus exposed to different concentration of poultry litter and different concentrations of bed containing $1 \mathrm{mg} / \mathrm{m}^{2}$. The treatments were similar by Dunnet post hoc test $(P>0.05)$. Mean and standard error.

\section{DISCUSSION}

In vitro results showed efficacy of the GML to control larval and adult forms of the mealworm Alphitobius diaperinus, which can be considered a new and potential alternative in the control of insects, since the treatment did not cause environmental impact when poultry litter was used as organic fertilizer, a common practice by poultry farmers.

In this study, GML treatment exerted larvicidal and insecticidal action in vitro against $A$. diaperinus, similarly to what was observed by researchers against bees [10], where this product was able to eliminate $55 \%$ of the bees after $120 \mathrm{~h}$ of treatment. It is important to emphasize that the aim of the study was to investigate toxic effects of GML against the bees [10], and not properly its insecticidal action. GML insecticidal mechanism of action is poorly investigated and remains unknown. However, there are evidences regarding its antimicrobial property
[12] using Staphylococcus aureus, Streptococcus spp., Enterococcus faecalis, as well as its capacity to inhibit some virulence factors linked to antimicrobial resistance $[5,15]$. The action mechanism linked to its antimicrobial properties is not totally elucidated, but some evidences suggest that GML affects the production of exoproteins through signal transduction pathway [14].

Some tests have been performed in order to reduce the use of chemical products, as observed by researchers [16] using Melaleuca alternifolia essential oil, popularly known as tea tree oil (TTO), that showed an excellent effect in controlling the larval form of mealworms without toxic effects to the soil. Similarly, studies demonstrated that Ocotea odorifera (popularly known as sassafras) and Eucalyptus viminalis (popularly known as eucalypt) essential oils exerts insecticidal action against the larvae and adults of mealworms, concluding that these treatments can be used to control 
these insects and used as a new integrated strategy to manage this pest. The main chemical used to control A. diaperinus is cypermethrin, a chemical product that can damage the soil fauna due to its intensive utilization [18]. In this study, the use of GML did not cause negative effects in the soil fauna, in disagreement with researchers [9] that studied GML at concentrations of 50 and $100 \mu \mathrm{g} \mathrm{mL}^{-1}$ and found negative effects on the soil fauna using adults and juvenile forms of springtails (Folsomia candida) as biomarkers, showing a LD50 of $41 \mu \mathrm{g} / \mathrm{mL}$. Based on these evidences, we can suggest that the toxicity of GML to soil fauna is related to the biomarker used to determine the toxicity. In summary, poultry litter after GML application can be used as pasture fertilizer without any detrimental impact to the soil fauna using the concentrations tested in this study while using the E. crypticus as contamination biomarker.
The use of GML was effective in the control of mealworm in both phases (larvae and adults) at concentration of $1 \mathrm{mg} \mathrm{mL}^{-1}$. In the ecotoxicological tests, GML did not show toxicity to soil, since it did not cause reproductive problems to Enchytraeus crypticus. In summary, GML can be used as a new alternative to control the lesser mealworm. To the best of our knowledge, this is the first study demonstrating the insecticidal action of GML against larval and adult forms of Alphitobius diaperinus, and we can conclude that this treatment can be an alternative to control it.

\section{MANUFACTURER}

${ }^{1}$ Seebio Biotech Inc. Xangain, China.

Declaration of interest. The authors report no conflicts of interest. The authors alone are responsible for the content and writing of the paper.

\section{REFERENCES}

1 Bautista D.A., Durisin M.D., Razavi-Rohani S.M., Hill A.R. \& Griffiths M.W. 1993. Extending the shelf-life of cottage cheese using monolaurin. Food Research International. 26(3): 203-208.

2 Do Prado G.P., Stefani L.M., Da Silva A.S., Smaniotto L.F., Garcia F.R.M. \& De Moura N.F. 2013. Alphitobius diaperinus (Coleoptera: Tenebrionidae) susceptibility to Cunila angustifolia essential oil. Journal of Medical Entomology. 50(5): 1040-1045.

3 Garcia M. 2004. Effects of pesticides on soil fauna: development of ecotoxicological test methods for tropical regions. [Bonn: Ecology and Development Series v.19]. Göttingen: Cuvillier Verlag, 254p.

4 Goodwin M.A. \& Waltman W.D. 1996. Transmission of Eimeria, viruses, and bacteria to chicks: darkling beetles (Alphitobius diaperinus) as vectors of pathogens. Journal of Applied Poultry Research. 5(1): 51-55.

5 Hess D.J., Henry-Stanley M.J. \& Wells C.L. 2015. The natural surfactant glycerol monolaurate significantly reduces development of Staphylococcus aureus and Enterococcus faecalis biofilms. Surgical Infections. 16(5): 538-542.

6 ISO 16387. 2004. Soil quality-effects of pollutants on Enchytraeidae (Enchytraeus sp.) determination of effects on reproduction and survival. International Organization for Standardization, Geneve, Switzerland.

7 ISO 11267. 1999. Soil quality - inhibition of reproduction of Collembola (Folsomia candida) by soil pollutants. International Organization for Standardization, Geneva, Switzerland.

8 Leschen R.A.B. \& Steelman C.D. 1988. Alphitobius diaperinus (Coleoptera: Tenebrionidae) larva and adult mouthparts. Entomology News. 99(2): 221-224.

9 Lopes L.Q., Santos C.G., Vaucher R.A., Raffin R.P., Da Silva A.S., Baretta D., de Ávila Scheeren C. 2017. Ecotoxicology of Glycerol Monolaurate nanocapsules. Ecotoxicology and Environmental Safety. 139(1): 73-77.

10 Lopes L.Q., Santos C.G., Vaucher R.A., Gende L., Raffin R.P. \& Santos R.C. 2016. Evaluation of antimicrobial activity of glycerol monolaurate nanocapsules against American foulbrood disease agent and toxicity on bees. Microbial Pathogenesis. 97(1): 183-188.

11 McAllister J.C., Steelman C.D., Newberry L.A. \& Skeeles J.K. 1995. Isolation of infectious bursal disease virus from the lesser mealworm, Alphitobius diaperinus (Panzer). Poultry Science. 74(1): 45-49.

12 Preuss H.G., Echard B., Enig M., Brook I. \& Elliott T.B. 2005. Minimum inhibitory concentrations of herbal essential oils and monolaurin for gram-positive and gram-negative bacteria. Molecular and Cellular Biochemistry. 272(1): 29-34.

13 Razavi-Rohani S.M. \& Griffiths M.W. 1994. The effect of mono and polyglycerol laurate on spoilage and pathogenic bacteria associated with foods. Journal of Food Safety. 14(2): 131-151. 
14 Ruzin A. \& Novick R.P. 2000. Equivalence of lauric acid and glycerol monolaurate as inhibitors of signal transduction in Staphylococcus aureus. Journal of Bacteriology. 182(9): 2668-2671.

15 Schlievert P.M. \& Peterson M.L. 2012. Glycerol monolaurate antibacterial activity in broth and biofilm cultures. Plos one. 7(7): e40350.

16 Volpato A., Lorenzetti W.R., Zortéa T., Giombelli L.C., Baretta D., Santos R.C.V., Vaucher R.A., Raffin R.P., Souza, M.E., Stefani L.M., Boligon A.A., Athayde M.L. \& Da Silva A.S. 2016. Melaleuca alternifolia essential oil against the lesser mealworm (Alphitobius diaperinus) and its possible effect on the soil fauna. Revista Brasileira de Ciência Avicola. 18(1): 41-46.

17 Wallace M.M.H., Winks R.G. \& Voestermans J. 1985. The use of a beetle, Alphitobius diaperinus (Panzer) (Coleoptera: Tenebrionidae) for the biological control of poultry dung in high-rise layer houses. Journal of the Australian Institute of Agricultural Science. 51(3): 214-219.

18 Zortéa T., Baretta D., Maccari A.P., Segat J.C., Boiago E.S., Sousa J.P. \& Da Silva A.S. 2015. Influence of cypermethrin on avoidance behavior, survival and reproduction of Folsomia candida in soil. Chemosphere. 122(1): 94-98. 